PHILOSOPHICAL TOPICS

VOL. 47, NO. 1, SPRING 2019

\title{
The Future of Predictive Ecology
}

\author{
Alkistis Elliott-Graves \\ University of Helsinki
}

\begin{abstract}
Prediction is an important aspect of scientific practice, because it helps us to confirm theories and effectively intervene on the systems we are investigating. In ecology, prediction is a controversial topic: even though the number of papers focusing on prediction is constantly increasing, many ecologists believe that the quality of ecological predictions is unacceptably low, in the sense that they are not sufficiently accurate sufficiently often. Moreover, ecologists disagree on how predictions can be improved. On one side are the 'theory-driven' ecologists, those who believe that ecology lacks a sufficiently strong theoretical framework. For them, more general theories will yield more accurate predictions. On the other are the 'applied' ecologists, whose research is focused on effective interventions on ecological systems. For them, deeper knowledge of the system in question is more important than background theory. The aim of this paper is to provide a philosophical examination of both sides of the debate: as there are strengths and weaknesses in both approaches to prediction, a pluralistic approach is best for the future of predictive ecology.
\end{abstract}

\section{INTRODUCTION}

In the mid-1980s, a group of scientists were investigating the effects of bird guano runoff on intertidal ecosystems in southwestern South Africa. In the course of their fieldwork, they made an interesting discovery that had no connection to the bird populations: the coastal waters around two islands, only $4 \mathrm{~km}$ apart, had radically different benthic communities. The first was covered in rock lobsters (Jasus lalandii) and had small densities of mussels and whelks (3 species of the Burnupena genus), while the second was covered in mussels and whelks and had no lobsters. According to the local fishermen, lobsters were present in both locations till the early 1970s, but then mysteriously disappeared from the second island. The scientists decided to investigate further. First, they conducted a field experiment to determine whether lobsters could still survive on the second island. Cages with lobsters were introduced to both islands (the set on the first island as a control) and all animals were still alive nine months later. Then, they conducted a second experiment to determine whether the low whelk density on the first island was due to predation by the lobsters. Mesh cages were installed in the reefs that allowed larvae of prey populations through 
but excluded lobsters. Sure enough, these areas were quickly recolonized by whelks. The final piece of the puzzle was to reintroduce lobsters to the second island, so that the species could become reestablished. A thousand healthy lobsters were simultaneously dropped into the waters of the second island. What happened then, was later described by one of the scientists as "a horror movie" (Wilcox 2018):

The apparently healthy rock lobsters were quickly overwhelmed by large numbers of whelks. Several hundreds were observed being attacked immediately after release and a week later no live rock lobsters could be found at Marcus Island. As damage during tagging may have triggered the attacks the experiment was repeated five times with smaller numbers (-20) of unmarked rock lobsters. Pairs of animals were recovered at 15-minute intervals after release and the attached whelks were counted. The rock lobsters escaped temporarily by swimming, but each contact with the substratum resulted in several more whelks attaching themselves until weight of numbers prevented escape. On average each rock lobster was killed within 15 minutes by more than 300 Burnupena that removed all the flesh in less than an hour. (Barkai and McQuaid 1988, 63, my emphasis)

This event was the first observed occurrence of 'predator-prey role reversal', where prey turn the tables on their predators and attack them. Since then, some other cases of predator-prey reversal have been observed in other ecosystems (Magalhes et al. 2005; Wizen and Gasith 2011). However, its main source of fame is as an example of how surprising ecological systems can be (Doak et al. 2008). There are many other examples of surprising ecological phenomena. A species of butterfly that adapted to an invader host (for oviposition) which had outcompeted its native host, but went locally extinct when the invader was eradicated, less than 20 years later (Singer and Parmesan 2018). In field experiments of plant-soil feedback, interactions between plants and soil microbes have been known to reverse, changing from positive to negative feedback (Casper and Castelli 2007; Klironomos 2002). Even within laboratory settings, there have been documented cases of unexpected changes in interactions between species (Benincà et al. 2008).

Many ecologists equate surprise with predictive failure (Beckage et al. 2011; Coreau et al. 2009; Doebeli and Ispolatov 2014; Ellner and Turchin 2015; France and Duffy 2006; Yodzis 1988). The reasoning for this is the following: scientists are surprised when their expectations are not met. When these expectations are expressed as hypotheses about the future states of the system, i.e. predictions, a surprise amounts to an inaccurate prediction. A high frequency of inaccurate predictions is often a sign of uncertainty regarding the phenomena being investigated, or more problematically, methods used to investigate them (Doak et al. 2008; Hitchcock and Sober 2004). In fact, the high frequency of predictive failure has led some ecologists to question the status of their discipline as truly scientific (Hayes and Barry 2007; Valéry et al. 2013). For others, the worry is predictions are insufficiently risky, in the sense that they are obvious or even tautological. This means that they cannot be falsified nor can they be used to refute existing theories - a mark of a nonscientific (or at least immature) discipline (Peters 1991). Interestingly, many of these critiques persist, despite establishment and growth of the community of predictive ecologists, whose work focuses on increasing the number and quality of predictions in the field (Mouquet et al. 2015). The worry is that despite great advances in data collection, availability, and manipulation, despite a better understanding of the causal mechanisms that give rise to ecological phenomena, for many 
ecologists, predictions are not sufficiently accurate sufficiently often (Houlahan et al. 2017; Marquet et al. 2014).

Moreover, ecologists' opinions vary significantly in terms of how this situation can be remedied. On one side are those who believe that ecology lacks a sufficiently strong theoretical framework. For them, the problem is that researchers are focusing too much on data-rich models and are failing to see the bigger picture, i.e. how seemingly disparate phenomena can be subsumed under general patterns or laws (Houlahan et al. 2017; McGill 2010; Ward et al. 2014). The idea is that the failure of predictions is a symptom of inadequate theories, so developing better theories will lead to better predictions. On the other side are those who believe that predictions should be more localized and take into account the context of each particular system. While they do not think that general background theories are irrelevant, they are more interested in intervening effectively on ecological systems. Thus, they usually advocate acquiring more in-depth knowledge about the particular systems being investigated in each case (Evans et al. 2012; Heger and Jeschke 2014; Kaunisto et al. 2016; Phillips et al. 2016).

The aim of this paper is to show that while both sides have made important contributions to ecological prediction, their arguments suffer from important limitations. I start by outlining the notion of surprise in ecology and its effect on predictive success (section 2). I then analyze the two most common suggestions for improving the accuracy of ecological predictions (section 3 ). The theory-driven approach has sound philosophical commitments, but is not best suited to ecological systems, as they are not merely complex, but also causally heterogeneous, leading to a tradeoff between generalizability and predictive power. I am more sympathetic to the opposing view, as it is better suited to the reality of ecological systems, though it suffers from an important practical limitation, namely that complex models sometimes do have low predictive accuracy. In section 4, I will suggest a way forward for predictive ecology that takes into account the pros and cons of each view.

\section{SURPRISE AND PREDICTIVE FAILURE}

Before delving into the issue of how to improve predictions, a little more needs to be said about surprise in ecology and its implications for prediction. As stated above, a common way for scientists to be surprised is if their hypotheses yield unexpected results. In the case of predictions, this happens when they turn out to be inaccurate. In traditional philosophy of science and theoretical ecology, an important mark of a successful theory is that it makes accurate predictions. Conversely, inaccurate predictions are caused by gaps in scientists' knowledge and show that there is something wrong with the frameworks, theories, or models they are using to investigate phenomena. Thus, theories that often yield surprising and inaccurate predictions are likely to be flawed. A traditional example of this type of surprise is the orbit of the planet Uranus, which was anomalous given the predictions of Newtonian mechanics. The story goes that the anomaly (along with others) showed that there were fundamental flaws in the Newtonian framework, and eventually led to its replacement by Einsteinian relativity (Thornton 2019). An example often mentioned in the ecological literature is Paine's surprising discovery that not all components of an 
ecosystem are equally important, but that some keystone species can have effects disproportionate to their relative size or abundance (Filbee-Dexter et al. 2017).

Of course, surprise is not always problematic, even if it results in the overturning of established theories. It is an integral aspect of scientific practice and features in all scientific disciplines. Moreover, scientists learn from surprises, and understanding why they occur, even in retrospect, leads to scientific progress (Morgan 2005; Parke 2014). Problems start when surprises occur too frequently or across many different models, theories, or frameworks. That is, when a discipline cannot produce new models, theories, or frameworks that succeed where the previous ones have failed or when the new models and theories also yield inaccurate predictions. A few failed predictions are to be expected in any science, but frequent failed predictions indicate that (i) there are problems in the underlying theories used to investigate the phenomena, (ii) there are methodological problems in the investigations, (iii) there are hidden factors or dynamics at work in the phenomena, or (iv) a combination of the above. As shown in the introduction, some ecologists take this worry quite seriously and claim that the frequency of surprises should cast doubt on many of the models, theories, or frameworks used to investigate ecological systems, so many that this doubt can be directed toward the discipline of ecology as a whole (Hayes and Barry 2007; Houlahan et al. 2017; Valéry et al. 2013).

How frequent are surprises in ecology? While it is not easy to make comparisons with other fields, there is some data on the frequency surprises within the discipline itself. Doak and colleagues (2008) conducted a survey of ecological surprises and found that they are far from rare occurrences. They outline at least 16 cases of famous surprises just within the subfields of population and community dynamics, and report that 98 percent of established field ecologists responding to a survey affirmed that they had encountered surprise events akin to the 16 paradigmatic cases in the paper. Moreover, many of the respondents also stated that the majority of surprising results had not been subsequently sent for publication, "the implication being that these observations were uninteresting, bothersome, embarrassing, or not sufficiently well chronicled and understood through proper application of the scientific method, and thus were underreported in the scientific literature" (p. 956, my emphasis).

What should we make of this particular frequency of surprise in ecology? I believe it explains the worries expressed by ecologists concerning the scientific status of their discipline, but that it does not justify them. While it is true that in some scientific disciplines, predictive failure often means that there is something wrong with the models or theories used to investigate phenomena, this is not the case in ecology. There are two reasons for this. First, the frequency of surprises is high but not extremely high. That is, there are many cases where ecologists are not surprised, and their predictions do not fail (Dambacher, Li, and Rossignol 2003; Evans, Norris, and Benton 2012a; Richardson and Rejmánek 2004). This is important because it shows that there are some patterns in ecology that are described accurately by models and theories.

Second, there is an alternative explanation for why surprises occur in ecology, and this explains a significant amount of predictive failure. Ecological systems are causally heterogeneous (Elliott-Graves 2018). Two systems are causally heterogeneous when they differ in terms of causal factors. The factors that give rise to a phenomenon or affect the outcome of a phenomenon in one 
system do not generalize to another system, nor do they remain unchanged in the future. In other words, it is often the patterns themselves in ecological systems that break. In cases like these, knowledge from one ecological system does not transfer to another, hence even when we know the mechanisms operating in one ecological system we might still fail to correctly predict the outcome of the same phenomenon in another system.

I should note that the notion of causal heterogeneity is distinct from the notion of complexity. A system is complex when it is made up of many interacting parts (Levins 1966; Matthewson 2011). Complexity can but need not contribute to causal heterogeneity. For example, a Boeing 747 is a complex system, yet each Boeing 747 is very similar to all the other Boeing $747 \mathrm{~s}$. Thus, finding out all the causally relevant factors in the operation of one allows us to generalize across different systems (Elliott-Graves 2018; Matthewson 2011). In contrast, a marine ecosystem and a forest ecosystem might have similar trophic levels, but the entities in each level are different and behave differently. In fact, some ecological systems exhibit causal heterogeneity even when they are ontologically similar. For instance, in plant-soil feedback (PSF) ${ }^{1}$ the same species of plants interact with the same species of soil microbes across different systems (e.g., geographically distinct prairies), yet these interactions are sometimes positive, sometimes neutral, and sometimes negative (Klironomos 2002). Even if scientists know the mechanisms by which PSF occurs and are able to explain particular instances of PSF, they are still not always able to predict each particular feedback outcome. Finally, as we saw in the case of the whelks and lobsters, systems and their parts can behave radically differently over time, even though the species within them are the same.

To sum up, the frequency of surprises in ecology is, in large part, due to the causal heterogeneity inherent in ecological systems. This heterogeneity explains why it is so difficult to make accurate predictions in the discipline. Nonetheless, improving the accuracy of ecological predictions is imperative, not because of general worries concerning the scientific status of the discipline, but because many of these surprises occur in applied contexts, i.e. when ecologists are trying to intervene on a particular system in order to induce, mitigate, or avoid a particular outcome. All too often, a failed prediction has real-world consequences, such as the local extinction of a species, the invasion of a species into a new area, or the creation of an even bigger ecological problem. A rather tragic example is the policy introduced for dealing with the invasive giant African land snail in the Pacific islands, which involved the introduction of a predatory snail. However, the introduced predatory snail preferred the native species to the invader, thus creating a much larger risk to the native pacific snail species (Thiengo et al. 2007).

How can the accuracy of ecological predictions be improved? There are two main suggestions in ecological literature, which I will discuss in the next section.

\footnotetext{
${ }^{1}$ Plants invariably interact with microbes in the soil, such as arbuscular mycorrhizal fungi and nutrient fixing bacteria. These interactions can be beneficial to the plant's growth (e.g., displacing plant pathogens) or detrimental (e.g., less access to nitrogen). Often, different feedback loops cancel each other out resulting in apparent neutral feedback.
} 


\section{IMPROVING ECOLOGICAL PREDICTIONS}

The debate around the status of prediction in ecology is one manifestation of a larger issue, that of the division between theoretical and applied ecology (Lawton 1996). Theoretical ecologists tend to approach ecological phenomena by reducing the complexity of ecological systems through highly abstract, mathematical, simple, and general models. Applied ecologists tend to deal with problems in particular systems, often using experiments or models that incorporate a lot of complexity. In truth, this distinction is not clear-cut, as most ecologists fall somewhere between the two extremes. Nonetheless, it is worth investigating because some ecologists - usually those who self-identify as theoreticians - decry the alleged shift in focus away from theory and toward application, citing it as the underlying cause of problems in ecology, especially regarding prediction (Courchamp et al. 2015; Houlahan et al. 2017; Marquet et al. 2014).

\subsection{FOCUS ON THEORY AND GENERALITY}

For theoretical ecologists, predictions are statements about the future state of a system that are derived from ecological theories (and data). An ecological theory is often understood as a conceptual framework that identifies the "essential features" of systems or phenomena (Marquet et al. 2014, 701). A successful theory, on this view, is one that is efficient, i.e. simple, parsimonious, derived from first principles, quantitative, and mathematical, with few inputs and many predictions (p. 704). ${ }^{2}$ For example, two fundamental principles of population ecology are: (i) exponential growth (expressed as $d N / d t=r N^{3}$ ) and (ii) limiting factors. The first principle describes how a population grows when it is not limited. The second principle can take many forms, including the effects of density (i.e., the competition for resources within a population), competition (between members of the population and members of other species' populations), and predation (Berryman 2003). The main theories of population ecology, e.g. competition, are built on these first principles.

Efficient theories "should yield a compressed description of the system or phenomenon under study, thereby reducing its complexity" (p. 703). In other words, efficient theories abstract away from the idiosyncratic details of each particular system, reducing the aspects of the system that need to be parametrized. ${ }^{4}$ This has two advantages. First, it allows scientists to distinguish between 'real' causal factors and mere details, thus gaining a more accurate picture of the dynamics of ecological systems. Second, it forms the basis of generalizations, as the real causal factors are also (thought to be) those that are common across different systems. So, an efficient theory is also general and unifying, because it reveals what is common between seemingly disparate systems.

\footnotetext{
${ }^{2}$ I should note this is not how philosophers usually interpret the term 'efficient'; this use comes from the ecological literature. Philosophers usually term these theories as simple, general, or even unifying (Kitcher 1981).

${ }^{3}$ Here, the equation describes how a population grows if it is not affected by any limiting factors. $N$ is the population size and $r$ is the intrinsic growth rate: the average number of offspring an individual has, at low density.

${ }^{4}$ See Raerinne (2018) for different notions of abstraction in ecological modeling.
} 
The types of models favored by this conceptual framework are also simple, in the sense that they have few equations and parameters, and general, in the sense that they apply to many different ecological systems (Holling 1966; May 2004). Examples include the exponential growth equation, mentioned above, and its variants that include limiting factors (such as the logistic model, the Lotka-Volterra competition and predation models and their variants). The aim of these models, like the theories that frame them, is to reduce the complexity of ecological systems and to identify core causal factors that are common across different systems.

On this view, efficient theories and their models should also yield successful predictions, because the theories and models are accurate and the predictions are based on real causal factors. In contrast, failures of prediction occur because there is something wrong with the background theories. The problem, for many theoretical ecologists, is that the theories have not correctly identified the essential features of the systems under investigation, i.e. have not identified the real causal factors at work (Houlahan et al. 2017; see also discussion in Maris et al. 2018). Consequently, the way to improve predictions is to find new or refine existing theories by making them more efficient, i.e. stripping them of confounding details so as to make sure that only the core causal factors are taken into account.

This view is supported by many historically influential philosophers of science. For many years, the prevailing view on scientific explanation was that good explanation is based on general laws or patterns and subsumes particular instances within these laws, thus unifying disparate phenomena (Hempel and Oppenheim 1948; Kitcher 1984, 1989). On many of these views, predictions follow naturally from general theories, because a prediction about the phenomenon under investigation doubles as a claim that the phenomenon is manifestation of a more general pattern. The idea that testing theories is an important function of prediction is also part of these views. Interestingly, even though the popularity of these traditional views in philosophy of science has waned in recent years, the idea that predictions function as tests of existing theories has remained important (Barrett and Stanford 2006; Hitchcock and Sober 2004; Lipton 2008). Even in more recent accounts of scientific explanation, such as certain types of causal or mechanistic accounts, philosophers place less value on unification yet preserve the importance of prediction as a means of testing theories (Levy and Bechtel 2012; Strevens 2004).

The problem with both the ecological and philosophical versions of this view is that they assume that laws, generalizations, or at the very least, a certain level of causal homogeneity holds in and across ecological systems. If we want to show that a phenomenon is an instance of a more general pattern, such a pattern must first be shown to exist. However, as we have seen, ecological systems display causal heterogeneity, i.e. the patterns exist but break. Importantly, causally heterogeneous systems differ in terms of relevant causal factors, not mere details. The 'idiosyncrasies' of each system, i.e. the aspects of a system not shared by other systems, are not irrelevant details, but causally relevant factors that affect the functioning of the system. Abstracting away these types of differences, by averaging them out or by omitting them altogether, can make a model's results highly and dangerously inaccurate.

For example, many causal factors that determine the outcome of competition are common to animal and plant populations. However, plant populations have a number of different causal factors 
that affect their ability to compete, most importantly the additional dynamic created by competition for resources between plant roots, which is, in turn, affected by dynamical interactions between plants, fungi, and bacteria (van der Putten et al. 2013). The importance of these additional dynamics becomes evident if we compare the relative predictive power of various competition models. Population-level models are meant to be simple and general, because they capture only the core features of competition that are common to animal and plant populations. Yet while they apply to animal populations, they often yield inaccurate results for plant populations (Berger et al. 2008). In contrast, individual-based models are flexible and can be constructed to include additional causal factors (Grimm et al. 2005). These have been shown to yield better results for plants (Evans et al. 2012). Even within this family of models, those which take into account additional factors such as below-ground competition and the heterogeneity of resources seem to be better at predicting the outcome of competition between plant populations (Phillips et al. 2016).

Theoretical ecologists may have a sound philosophical basis for their claims that ecological predictions fail because the background theories that give rise to them are not sufficiently general, yet this framework does not seem to fit the reality of ecological systems, which are complex and heterogeneous. I will now turn to the alternative suggestion for improving predictions, which stems from applied ecological research.

\subsection{FOCUS ON DETAIL AND INCORPORATING COMPLEXITY}

The main aim of applied ecology is to solve particular problems that manifest in ecological ecosystems, such as population extinctions, biological invasions, conservation of biodiversity, etc. Solving these problems often occurs through direct interventions on the system in question, with theory operating in the background. The resulting approach is rich in data and detail, as applied ecologists usually aim to gain in-depth knowledge about each system under investigation. Their models also tend to be data-rich and aim to incorporate rather than reduce complexity. For example, niche distribution models such as GARP (Genetic Algorithm for Rule-set Prediction) incorporate a very large number of parameters that make up an organism's niche, and compare that niche to other areas with high levels of parameter similarity (figure 3). They can be used to make predictions about the spread of a particular species to new areas (Peterson and Vieglais 2001; Sobek-Swant et al. 2012). 
Figure 3. GARP for Japanese Longhorn Beetle
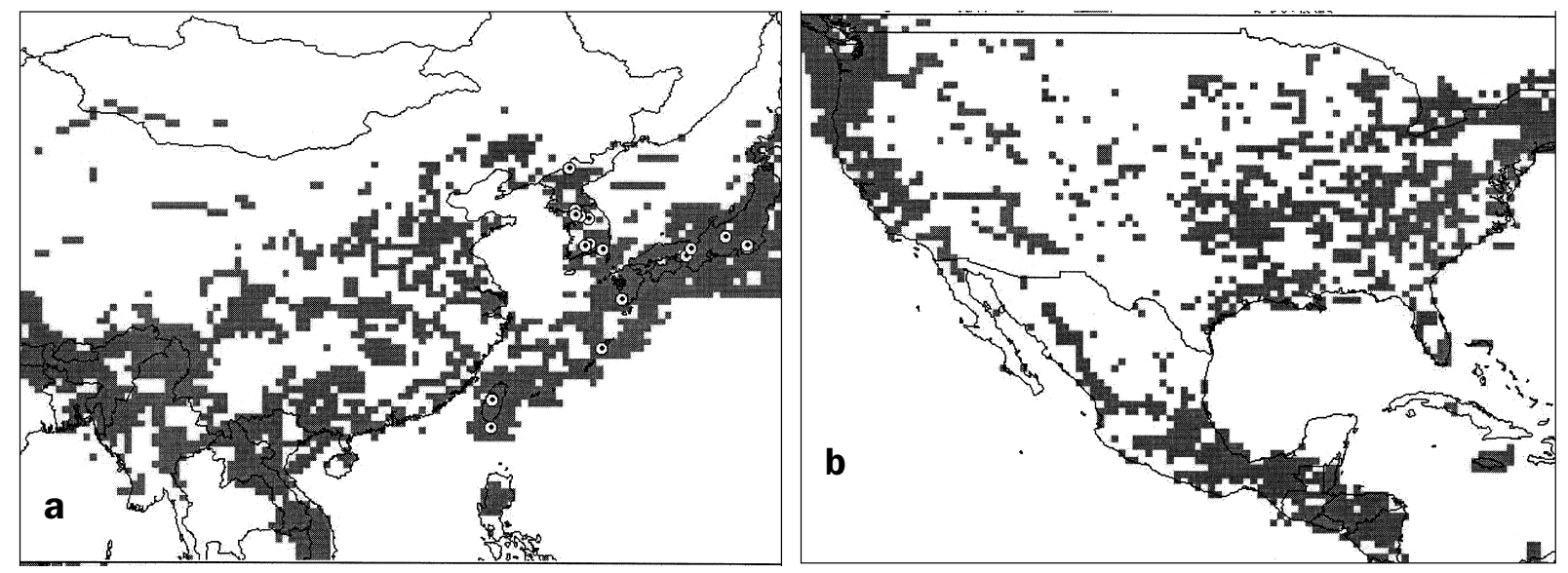

Distributional modeling efforts for the Japanese white-spotted citrus longhorn beetle (Anoplophora malasiaca). (a) Distributional points and modeled distribution in southern and eastern Asia, and (b) potential distribution in North America. (Adapted from Peterson and Vieglais 2001)

Applied ecologists usually explain cases of failed prediction by citing the inherent complexity and idiosyncrasies of ecological systems. They take seriously the fact that if seemingly similar systems have idiosyncratic causal factors, then the knowledge gained from studying one system might not be generalizable to others. An interesting example comes from the study of insect overwintering strategies. Insects face a number of environmental and biotic stressors, such as temperature, pathogens, and toxins, that affect their behavior and their ability to survive, especially during the winter months (Kaunisto et al. 2016). One strategy for dealing with harsh winters is for insects to produce a kind of antifreeze in their haemolymph (Sinclair et al. 2003). The mechanism for the production of these antifreeze proteins is understood quite well for a number of insect species, yet this does not necessarily mean that the outcome for each insect population can be predicted. For instance, if the winter is generally mild, insects can produce less antifreeze protein and have higher energy reserves in the spring, yet if the winter temperatures rise often and above a certain threshold, insects can burn through more of their energy reserves. In some cases, this means that they can survive the winter, but are less capable of reproducing during the spring (Sinclair et al. 2003). Finally, if there are repeated freezing events at the beginning of the winter, then some insects become increasingly less capable of producing the antifreeze proteins. This may not always be a problem, e.g. if they are under snow cover (temperatures under snow cover are stable and relatively warm, i.e. close to $0^{\circ} \mathrm{C}$ ) but can result in high mortality rates if they are subsequently subjected to spells of much lower temperatures (Marshall and Sinclair 2012). The difficulties of predicting insect responses to stressors are summarized in Box 1 (figures taken from Kaunisto et al. 2016). 


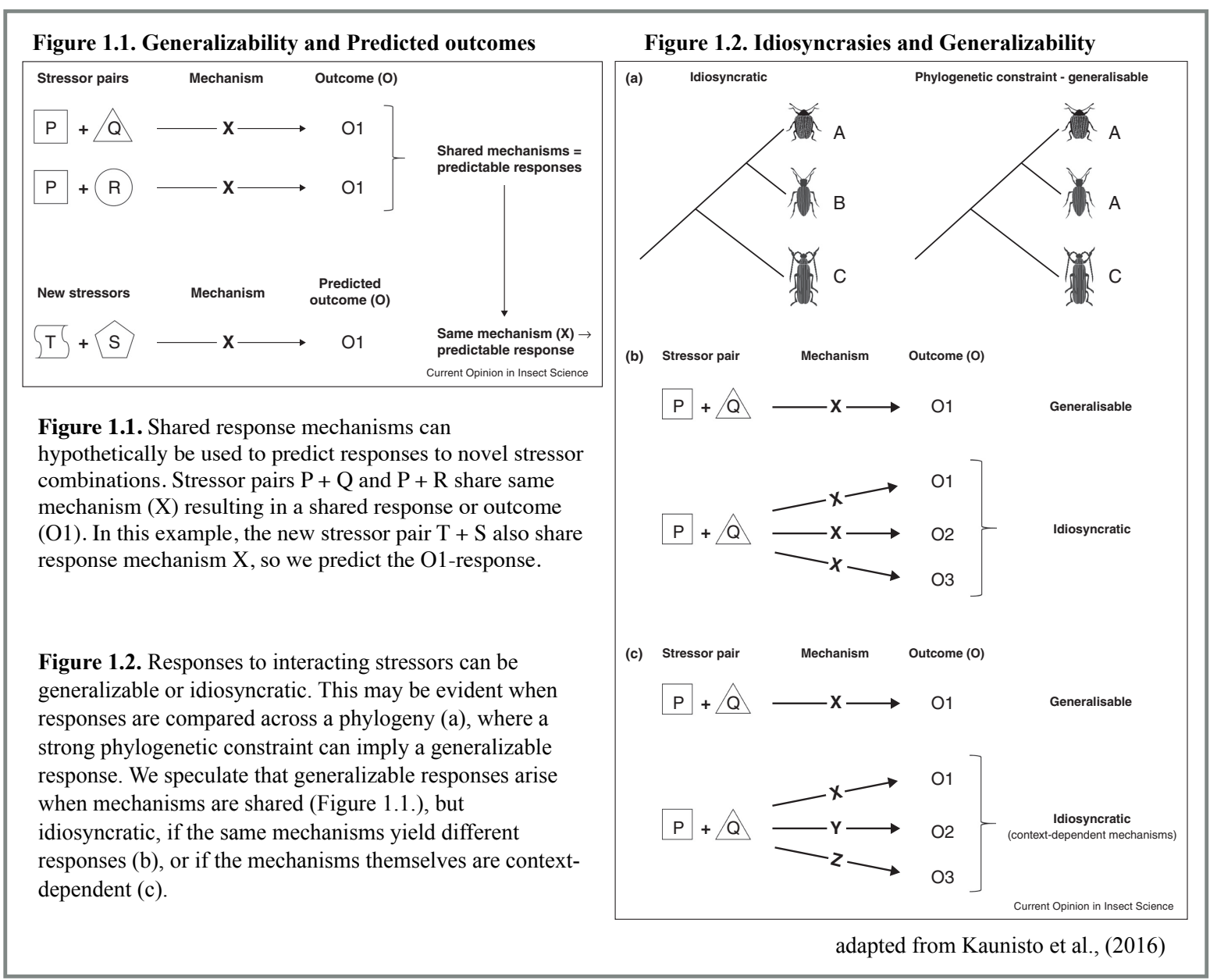

\section{Box 1. Idiosyncrasies, Generalizability, and Prediction in Insect Responses to Environmental Stressors}

The suggestions of applied ecologists for improving ecological predictions vary to some extent, but share a common theme, namely trying to better represent the complexity and heterogeneity of ecological ecosystems. The variation is in terms of how this can be achieved. Some applied ecologists suggest focusing more on experimentation rather than modeling, especially field experiments, as they support experimental designs that incorporate a lot of complexity (Brinkman et al. 2010; Kareiva, Parker, and Pascual 1996; Thrush et al. 2000). Others suggest a turn toward process-based ecological models, such as individual-based models, that can include a large number of parameters and thus take into account idiosyncrasies of particular systems (Evans et al. 2012; Grimm et al. 2005). Others still, suggest adapting complex predictive models from adjacent fields dealing with similar problems, such as fisheries, epidemiology, and forestry (Pennekamp et al. 2017; Pielke and Conant 2003).

The first problem with the applied ecological approach to prediction is that it can lead to extreme localism, i.e. where the results of a study are only applicable within the context of that study and cannot be transferred to any other system (Guala 2003). If models or experiments are 
tailor-made for particular systems, and those systems are idiosyncratic (i.e., have high levels of causal heterogeneity), then including all the relevant factors that give rise to the phenomenon in that system means that the model will not be applicable or informative for any other system. Moreover, even tailor-made approaches will not protect from surprises that occur within a system, if causal heterogeneity manifests in the same system across time. For example, a model that includes all the factors contributing to a positive feedback loop between plants and soil microbiota may fail to predict a correct outcome if that positive loop becomes negative. Now, we might be forced to concede that in some cases, this outcome is inevitable. However, the worry is that by adopting the tailor-made approach, applied ecologists might miss the opportunity to identify commonalities between systems when they do occur. If there are any patterns in the ecological world, it is extremely important that they are identified!

I do not believe that this problem is insurmountable. There is an abundance of papers in the literature that actively look for patterns across systems, within certain constraints (see for example Heger and Jeschke 2014; Linquist et al. 2016; Phillips et al. 2016; Richardson and Rejmánek 2004). This is often achieved by large-scale statistical analysis of existing data sets, or metaanalyses of existing papers, which examine tailor-made models or experiments. For example, a study of invasive and noninvasive species of pines showed that invaders shared three important traits: small seed mass, small juvenile periods, and short intervals between seed crops (Rejmánek and Richardson 1996; Richardson and Rejmánek 2004). This sort of study proved to be extremely useful, as the authors were able to identify species of pines that pose particular threats to ecosystems. For example, they identified $P$. radiata, $P$. contorta, $P$. halepensis, $P$. patula, $P$. pinaster as the five most invasive species of pine and also identified 14 species of pine that do not pose a threat to invasion. More specifically, they also identified particular forests in Sweden as a potential danger zone, as they are susceptible to invasion by the North American P. contorta. The important difference between this approach to generality and that of the theoretical ecologists is that the existence of patterns is investigated rather than assumed. Consequently, the generalizations are modest, in the sense that they apply only within certain parameters, such as a particular species, genus, or geographical location.

The second issue with this approach concerns low-quality data sets: often, the data ecologists need are difficult to obtain, or even unavailable. For example, the capture-recapture method is perhaps the most widely used sampling method in ecology yet does not work equally well for all species/populations. It is not very useful in cases where capture or recapture is difficult, and it can result in biased samples. For instance, in some fish species, capture methods are biased toward larger fish, skewing demographic information (Pine et al. 2003). All models have some chance of prediction error when they are based on low-quality data, yet the more complex models, favored in the applied approach, are likely to result in higher levels of prediction error (Novak et al. 2011; Perretti and Munch 2013). There are two reasons for this. The first is the increased risk of overfitting (Hitchcock and Sober 2004). According to the Akaike framework, models with many parameters are in greater danger of fitting the data too well, in the sense that they can be trained extremely efficiently on the original data sets. The problem is that this makes them oversensitive to data points that are outliers or even noise, which decreases the likelihood that they will yield 
accurate predictions. The second reason is that, as errors can be introduced every time a model's parameter is estimated from low-quality data, more complex models have more parameters, so each additional parameter contributes to the likelihood of error (Novak et al. 2011). Moreover, in complex models, parameters interact with each other, so the effect of each error is magnified and passed on to other parameters. In short, while simple models tend to be accurate on fewer occasions, when compared to more complex models, the latter tend to have greater margins of error, when inaccurate.

This issue is much more problematic for the second approach, because the practical limitation of patchy data is here to stay (Tucker and Duplisea 2012). That is, it seems unlikely that our data sets will be greatly improved in the foreseeable future. Ecologists are using state-of-the-art data collection methods, and while there have been some technological advances over the last decades, data sets remain patchy and skewed, especially in some types of ecosystems (e.g., marine ecosystems where (a) population sizes are incredibly difficult to estimate and (b) a lot of data comes from fishermen - who have an obvious motivation to underreport their catches or misrepresent the relative abundances of various fish populations) (National Research Council 2000).

\section{THE FUTURE OF PREDICTIVE ECOLOGY}

At this point, the future of predictive ecology may seem rather grim. I have argued that the theoretical approach is doomed to fail, as it cannot capture the complexity and heterogeneity of ecological systems. Yet the applied approach is also problematic, as complex models of lowquality data sets have high rates of predictive failure. I propose that the way forward is a hybrid of the two approaches which retains the best aspects of both. Two aspects should be retained from each approach. The first is the importance of generalization from the first approach. Generalizations are useful because they allow scientists to compare different systems and to identify patterns in the world. If there are patterns, we want to be able to find them. There is a big caveat, however. All this can be achieved with quite modest generalizations. Thus, the methods for generalizing should come from the second approach. Instead of searching for a theoretical framework to unify all of ecology, or even all community or invasion biology (see Houlahan et al. 2017), ecologists should be content with generalizations with a much more restricted scope. What is the appropriate scope? This can only be determined on a case-by-case basis, as it depends on whether two or more systems have sufficient causal homogeneity. Still, a second suggestion for attaining generalizations is for theoretical ecologists (i.e., those concerned about the lack of generality in ecology) to recognize the usefulness of bottom-up, modest generalizations, especially those used in the generation of systematic reviews and meta-analyses. These approaches do not assume that generalizations hold, but test the scope of generalizations across different taxa/systems (Gurevitch et al. 2018; Heger and Jeschke 2014). Hence, they are much less likely to result in overgeneralization and the omission of relevant causal factors.

The second issue is to determine which models should be favored for ecological predictions. As we have seen, simple models cannot incorporate complexity and thus have systematic errors, 
yet complex models, though they have a lower frequency of error, have a much higher magnitude of prediction error, given the patchiness of available data. I believe that the answer is to favor more complex models over simple models, as they are correct more often, but with an important caveat, namely that ecologists should be wary of the likelihood of error in their models and take steps to minimize error. I believe that the following are the two most fruitful ways to minimize error. First, ecologists should focus on models that are flexible rather than maximally complex. These are models that can be altered to capture different groups of parameters, depending on which are considered relevant. The first advantage is that flexible models can leave out error-inducing parameters if they are deemed to be irrelevant. Second, the models can be run with various combinations of factors, so as to determine the effect of parameters on the overall model output. In other words, the models' flexibility can be used to test the sensitivity of the model output to particular biases in the data. An example of such models are IBMs, which can be adapted to suit the peculiarities of particular systems. For example, a group of scientists recently showed that the performance of the FORMIND Forest Model (an IBM) was hampered by considering only one plant functional type (groupings of species based on important characteristics such as fecundity and competitiveness) (Fischer et al., 2018). However, they also found that there was no need to use a different model, because the model was sufficiently flexible to allow for the representation of additional plant functional groups, and found that the performance of the model reached the appropriate level of accuracy when (i) it included three plant functional types and (ii) one of these groups represented pioneer species (those that are first to colonize a disturbed/barren area).

The second suggestion is a more extreme version of flexibility, which includes using more than one model with different levels of complexity, or using hybrid models that combine elements of two different models (Gallien et al. 2010). Of course, this is not always feasible, but in some cases, using multiple models with radically different assumptions can provide more robust predictions (Weisberg 2006). Thus, sometimes, ecologists might wish to use both simple and complex models, to check whether they produce similar predictions.

\section{CONCLUSION}

The future of predictive ecology is conceptually straightforward, but difficult to implement practically. That is, there is no need for a conceptual rehaul of ecology, or for the search of new theoretical frameworks. Instead, what is needed is the realization that the causal heterogeneity of ecological systems means that generalizations will be necessarily limited in scope, and that models will have high rates of predictive error. This predictive error is due to heterogeneity and lowquality data sets and can be combatted on a case-by-case basis, by checking and rechecking each model's performance in a given context. In addition, theoretical ecologists can utilize various methods for generalizing and testing the scope of generalizations and predictions from the literature on systematic review, meta-analysis, and other types of formalized synthesis. 


\section{REFERENCES}

Barkai, A., and C. McQuaid. 1988. "Predator-Prey Role Reversal in a Marine Benthic Ecosystem." Science 242(4875): 62-64. http://doi.org/10.1126/science.242.4875.62.

Barrett, J., and P. K. Stanford. 2006. "Prediction." In The Philosophy of Science: An Encyclopedia, edited by J. Pfeifer and S. Sarkar. New York: socsci.uci.edu.

Beckage, B., L. J. Gross, and S. Kauffman. 2011. "The Limits to Prediction in Ecological Systems." Dx.Doi.org 2(11): art125. http://doi.org/10.1890/ES11-00211.1.

Berryman, A. (2003). On Principles, Laws and Theory in Population Ecology. Oikos, 103(3), 695-701.

Benincà, E., J. Huisman, R. Heerkloss, K. D. Jöhnk, P. Branco, E. H. van Nes, et al. 2008. "Chaos in a Long-Term Experiment with a Plankton Community." Nature 451(7180): 822-25. http://doi.org/10.1038/nature06512.

Berger, U., C. Piou, K. Schiffers, and V. Grimm. 2008. "Competition among Plants: Concepts, Individual-Based Modelling Approaches, and a Proposal for a Future Research Strategy." Perspectives in Plant Ecology, Evolution and Systematics 9(3-4): 121-35. http://doi.org/10.1016/j.ppees.2007.11.002.

Brinkman, E. P., W. H. van der Putten, E. J. Bakker, and K. J. F. Verhoeven. 2010. "Plant-Soil Feedback: Experimental Approaches, Statistical Analyses and Ecological Interpretations." Journal of Ecology 98(5): 1063-73. http://doi.org/10.1111/j.13652745.2010.01695.x.

Casper, B. B., and J. P. Castelli. 2007. "Evaluating Plant-Soil Feedback Together with Competition in a Serpentine Grassland." Ecology Letters 10(5): 394-400. http://doi.org/10.1111/j.1461-0248.2007.01030.x.

Coreau, A., G. Pinay, J. D. Thompson, P. O. Cheptou, and L. Mermet. 2009. "The Rise of Research on Futures in Ecology: Rebalancing Scenarios and Predictions." Ecology Letters 12(12): 1277-86. http://doi.org/10.1111/j.1461-0248.2009.01392.x.

Courchamp, F., Dunne, J.A., Le Maho, Y., May, R.M., Thebaud, C. \& Hochberg, M.E. (2015). Fundamental ecology is fundamental. Trends in Ecology and Evolution, 30, 9-16.

Dambacher, J. M., H. W. Li, and P. A. Rossignol. 2003. "Qualitative Predictions in Model Ecosystems." Ecological Modelling 161(1-2): 79-93. http://doi.org/10.1016/S03043800(02)00295-8.

Doak, D. F., J. A. Estes, B. S. Halpern, U. Jacob, D. R. Lindberg, and J. Lovvorn, et al. 2008. "Understanding and Predicting Ecological Dynamics: Are Major Surprises Inevitable?" Ecology 89(4): 952-61. http://doi.org/10.1890/07-0965.1.

Doebeli, M., and I. Ispolatov. 2014. "Chaos and Unpredictability in Evolution." Evolution 68(5): 1365-73. http://doi.org/10.1111/evo.12354.

Elliott-Graves, A. (2018) 'Generality and Causal Interdependence in Ecology' Philosophy of Science 85(1) 1102-1114

Ellner, S., and P. Turchin. 2015. "Chaos in a Noisy World: New Methods and Evidence from Time-Series Analysis.” American Naturalist 145(3): 343-75. http://doi.org/10.1086/285744.

Evans, M. R., K. J. Norris, and T. G. Benton. 2012a. "Predictive Ecology: Systems Approaches." Philosophical Transactions of the Royal Society B: Biological Sciences 367(1586): 16369. http://doi.org/10.1098/rstb.2011.0191. 
Filbee-Dexter, K., J. Pittman, H. A. Haig, S. M. Alexander, C. C. Symons, and M. J. Burke. 2017. "Ecological Surprise: Concept, Synthesis, and Social Dimensions." Ecosphere (Vol. 8). John Wiley \& Sons. http://doi.org/10.1002/ecs2.2005.

Fischer, R., E. Rodig, and A. Huth. 2018. "Consequences of a Reduced Number of Plant Functional Types for the Simulation of Forest Productivity." Forests 9(8): 460. http://doi.org/10.3390/f9080460.

France, K. E., and J. E. Duffy. 2006. "Diversity and Dispersal Interactively Affect Predictability of Ecosystem Function." Nature 441(7097): 1139-43. http://doi.org/10.1038/nature04729.

Gallien, L., T. Münkemüller, C. H. Albert, I. Boulangeat, and W. Thuiller. 2010. "Predicting Potential Distributions of Invasive Species: Where to Go from Here?" Diversity and Distributions 16(3): 331-42. http://doi.org/10.1111/j.1472-4642.2010.00652.x.

Grimm, V., E. Revilla, U. Berger, F. Jeltsch, W. M. Mooij, S. F. Railsback, et al. 2005. "PatternOriented Modeling of Agent-Based Complex Systems: Lessons from Ecology." Science 310(5750): 987-91.

Guala, F. 2003. "Experimental Localism and External Validity." Philosophy of Science 70(5): 1195-1205. http://doi.org/10.1086/377400.

Gurevitch J., Koricheva, J., Nakagawa, S., Stewart, G., 2018 "Meta-analysis and the science of research synthesis", Nature 555(175): 175-182.

Hayes KR, Barry SC, 2007 “Are there any consistent predictors of invasion success?” Biological Invasions 10(4):483-506

Heger, T., and J. M. Jeschke. 2014. "The Enemy Release Hypothesis as a Hierarchy of Hypotheses." Oikos 123(6): 741-50. http://doi.org/10.1111/j.1600-0706.2013.01263.x.

Hempel, C. G., and P. Oppenheim. 1948. "Studies in the Logic of Explanation." Philosophy of Science 15(2): 135-75. http://doi.org/10.2307/185169?ref=searchgateway:0c1dbed607f660b0c1569ddf721ed555.

Hitchcock, C., and E. Sober. 2004. "Prediction Versus Accommodation and the Risk of Overfitting." British Journal for the Philosophy of Science 55(1): 1-34. http://doi.org/10.1093/bjps/55.1.1.

Holling, C. S. 1966. "The Strategy of Building Models of Complex Ecological Systems.” In Systems Analysis in Ecology, edited by K. E. F. Watt, Academic Press, New York. pp. 195-214.

Houlahan, J. E., S. T. McKinney, T. M. Anderson, and B. J. McGill. 2017. "The Priority of Prediction in Ecological Understanding." Oikos 126(1): 1-7. http://doi.org/10.1111/oik.03726.

Kareiva, P., I. M. Parker, and M. Pascual. 1996. "Can We Use Experiments and Models in Predicting the Invasiveness of Genetically Engineered Organisms?” Ecology 77(6): 1670. http://doi.org/10.2307/2265771.

Kaunisto, S., L. V. Ferguson, and B. J. Sinclair. 2016. "Can We Predict the Effects of Multiple Stressors on Insects in a Changing Climate?" Current Opinion in Insect Science 17:5561. http://doi.org/10.1016/j.cois.2016.07.001.

Kitcher, P. 1981. "Explanatory Unification." Philosophy of Science 48(4): 507-31. http://doi.org/10.2307/186834.

Kitcher, P. 1984. "1953 and All That: A Tale of Two Sciences.” Philosophical Review 93(3): 335. http://doi.org/10.2307/2184541.

Kitcher, P. 1989. "Explanatory Unification and the Causal Structure of the World." Scientific Explanation 13:410-505. 
Klironomos, J. N. 2002. "Feedback with Soil Biota Contributes to Plant Rarity and Invasiveness in Communities." Nature 417(6884): 67-70.

Lawton, J. 1996. "Corncrake Pie and Prediction in Ecology". Oikos 76(1): 3-4.

Levins, R. 1966. "The Strategy of Model Building in Population Biology." American Scientist 54(4): 421-31. http://doi.org/10.2307/27836590.

Levy, A., and W. Bechtel. 2012. "Abstraction and the Organization of Mechanisms." Philosophy of Science 80(2): 241-61. http://doi.org/10.1086/670300.

Linquist, S., T. R. Gregory, T. A. Elliott, B. Saylor, S. C. Kremer, and K. Cottenie. 2016. "Yes! There Are Resilient Generalizations (or 'Laws') in Ecology." Quarterly Review of Biology 91(2): 119-31. http://doi.org/10.1086/686809.

Lipton, P. 2008. "Prediction and Prejudice." International Studies in the Philosophy of Science 4(1): 51-65. http://doi.org/10.1080/02698599008573345.

Magalhes, S., A. Janssen, M. Montserrat, and M. W. Sabelis. 2005. "Prey Attack and Predators Defend: Counterattacking Prey Trigger Parental Care in Predators." Proceedings of the Royal Society B: Biological Sciences 272(1575): 1929-33.

Maris, V., P. Huneman, A. Coreau, S. Kéfi, R. Pradel, and V. Devictor. 2018. "Prediction in Ecology: Promises, Obstacles and Clarifications.” Oikos 127(2): 171-83. http://doi.org/10.1111/oik.04655.

Marquet, P. A., A. P. Allen, J. H. Brown, J. A. Dunne, B. J. Enquist, J. F. Gillooly, et al. 2014. "On Theory in Ecology." BioScience 64(8): 701-10. http://doi.org/10.1093/biosci/biu098.

Marshall, K. E., and B. J. Sinclair. 2012. "Threshold Temperatures Mediate the Impact of Reduced Snow Cover on Overwintering Freeze-Tolerant Caterpillars." Naturwissenschaften 99(1): 33-41. http://doi.org/10.1007/s00114-011-0866-0.

Matthewson, J. 2011. "Trade-offs in Model-Building: A More Target-Oriented Approach." Studies in History and Philosophy of Science Part A 42(2): 324-33. http://doi.org/10.1016/j.shpsa.2010.11.040.

May, R. M. 2004. "Uses and Abuses of Mathematics in Biology." Science 303(5659): 790-93. http://doi.org/10.1126/science.1094442.

McGill, B. J. 2010. "Towards a Unification of Unified Theories of Biodiversity." Ecology Letters 13(5): 627-42. http://doi.org/10.1111/j.1461-0248.2010.01449.x.

Morgan, M. S. 2005. "Experiments versus Models: New Phenomena, Inference and Surprise." Journal of Economic Methodology 12(2): 317-29. http://doi.org/10.1080/13501780500086313.

Mouquet, N., et al. 2015. REVIEW: predictive ecology in a changing world. Journal of Applied Ecology 52:1293-1310.

National Research Council. 2000. "General Issues in the Collection, Management, and Use of Fisheries Data." In Improving the Collection, Management, and Use of Marine Fisheries Data. Washington, DC.

Novak, M., J. T. Wootton, D. F. Doak, M. Emmerson, J. A. Estes, and M. T. Tinker. 2011. "Predicting Community Responses to Perturbations in the Face of Imperfect Knowledge and Network Complexity." Ecology 92(4): 836-46. http://doi.org/10.1890/10-1354.1.

Parke, E. C. 2014. Experiments, Simulations, and Epistemic Privilege. Philosophy of Science 81(4): 516-536

Pennekamp, F., M. W. Adamson, O. L. Petchey, J.-C. Poggiale, M. Aguiar, B. W. Kooi, et al. 2017. "The Practice of Prediction: What Can Ecologists Learn from Applied, EcologyRelated Fields?" Ecological Complexity 32:156-67. http://doi.org/10.1016/j.ecocom.2016.12.005. 
Perretti, C. T., and S. B. Munch. 2013. "Model-Free Forecasting Outperforms the Correct Mechanistic Model for Simulated and Experimental Data." Proceedings of the Natural Academy of Sciences USA 110 (5253-5257)

http://doi.org/10.1073/pnas.1216076110/-/DCSupplemental.

Peters, R. 1991. A Critique for Ecology. Cambridge: Cambridge University Press.

Peterson, A. T., and D. A. Vieglais. 2001. "Predicting Species Invasions Using Ecological Niche Modeling: New Approaches from Bioinformatics Attack a Pressing Problem: A New Approach to Ecological Niche Modeling, Based on New Tools Drawn from Biodiversity Informatics, Is Applied to the Challenge of Predicting Potential Species' Invasions." BioScience 51(5): 363-71. http://doi.org/10.1641/00063568\%282001\%29051\%5B0363\%3APSIUEN\%5D2.0.CO\%3B2.

Phillips, R. P., I. Ibanez, and L. D'Orangeville. 2016. "A Belowground Perspective on the Drought Sensitivity of Forests: Towards Improved Understanding and Simulation." Forest Ecology and Management 380, 309-320.

Pielke, R. A., and R. T. Conant. 2003. "Best Practices in Prediction for Decision-Making: Lessons from the Atmospheric and Earth Sciences." Ecology 84(6): 1351-58. http://doi.org/10.1890/0012-9658(2003)084[1351:BPIPFD]2.0.CO;2.

Pine, W. E., K. H. Pollock, J. E. Hightower, T. J. Kwak, and J. A. Rice. 2003. "A Review of Tagging Methods for Estimating Fish Population Size and Components of Mortality." Fisheries 28(10): 10-23. http://doi.org/10.1577/15488446(2003)28[10:AROTMF]2.0.CO;2.

Raerinne, J. 2018. "Abstraction in Ecology: Reductionism and Holism as Complementary Heuristics.” European Journal for Philosophy of Science 8(3): 395-416. http://doi.org/10.1007/s13194-017-0191-3.

Rejmánek, M., and D. M. Richardson. 1996. "What Attributes Make Some Plant Species More Invasive?” Ecology 77(6): 1655-61.

Richardson, D. M., and M. Rejmánek. 2004. "Conifers as Invasive Aliens: A Global Survey and Predictive Framework." Diversity and Distributions 10(5-6): 321-31.

Sinclair, B. J., P. Vernon, C. Jaco Klok, and S. L. Chown. 2003. "Insects at Low Temperatures: An Ecological Perspective.” Trends in Ecology \& Evolution 18(5): 257-62. http://doi.org/10.1016/S0169-5347(03)00014-4.

Singer, M. C., and C. Parmesan. 2018. "Lethal Trap Created by Adaptive Evolutionary Response to an Exotic Resource." Nature 557(7704): 238-41. http://doi.org/10.1038/s41586-0180074-6.

Sobek-Swant, S., D. A. Kluza, K. Cuddington, and D. B. Lyons. 2012. "Potential Distribution of Emerald Ash Borer: What Can We Learn from Ecological Niche Models Using Maxent and GARP?" Forest Ecology and Management 281:23-31. http://doi.org/10.1016/j.foreco.2012.06.017.

Strevens, M. 2004. "The Causal and Unification Approaches to Explanation Unified - Causally." Noûs 38(1): 154-76.

Thiengo, S. C., F. A. Faraco, N. C. Salgado, R. H. Cowie, and M. A. Fernandez. 2007. "Rapid Spread of an Invasive Snail in South America: The Giant African Snail, Achatina fulica, in Brasil." Biological Invasions 9(6): 693-702. http://doi.org/10.1007/s10530-006-9069$\underline{6}$.

Thrush, S. F., J. E. Hewitt, V. J. Cummings, and M. O. Green. 2000. "The Generality of Field Experiments: Interactions between Local and Broad-Scale Processes." Ecology. http://doi.org/10.1890/0012-9658(2000)081\%5B0399:TGOFEI\%5D2.0.CO;2/full. 
Valéry, Loïc, Hervé Fritz, and Jean-Claude Lefeuvre. 2013. "Another Call for the End of Invasion Biology." Oikos 122 (8): 1143-46.

Thornton, Stephen, (2019) "Karl Popper", The Stanford Encyclopedia of Philosophy (Winter 2019 Edition), Edward N. Zalta (ed.), URL = $<$ https://plato.stanford.edu/archives/win2019/entries/popper/>.

Tucker, A., and D. Duplisea. 2012. "Bioinformatics Tools in Predictive Ecology: Applications to Fisheries.” Philosophical Transactions of the Royal Society B: Biological Sciences 367(1586): 279-90. http://doi.org/10.1098/rstb.2011.0184.

van der Putten, W. H., R. D. Bardgett, J. D. Bever, T. M. Bezemer, B. B. Casper, T. Fukami, et al. 2013. "Plant-Soil Feedbacks: The Past, the Present and Future Challenges." Journal of Ecology 101(2): 265-76. http://doi.org/10.1111/1365-2745.12054.

Ward, E. J., E. E. Holmes, J. T. Thorson, and B. Collen. 2014. "Complexity Is Costly: A Metaanalysis of Parametric and Non-Parametric Methods for Short-Term Population Forecasting." Oikos 123(6): 652-61. http://doi.org/10.1111/j.1600-0706.2014.00916.x.

Weisberg, M. 2006. "Robustness Analysis.” Philosophy of Science 73(5): 730-42. http://doi.org/10.1086/518628.

Wilcox, C. 2018, August 27. "When Snails Attack: The Epic Discovery of an Ecological Phenomenon.” Discover.

Wizen, G., and A. Gasith. 2011. "An Unprecedented Role Reversal: Ground Beetle Larvae (Coleoptera: Carabidae) Lure Amphibians and Prey upon Them.” PloS One 6(9): e25161. http://doi.org/10.1371/journal.pone.0025161.

Yodzis, P. 1988. "The Indeterminacy of Ecological Interactions as Perceived through Perturbation Experiments." Ecology 69(2): 508-15. http://doi.org/10.2307/1940449. 